\title{
Produção e Avaliação de Videoaulas: Um Estudo de Caso no Ensino de Programação
}

\author{
André Raabe ${ }^{1,2}$, André Bernardes ${ }^{1}$, Roberto Gonçalves Augusto Junior ${ }^{1}$ \\ ${ }^{1}$ Mestrado em Computação Aplicada \\ ${ }^{2}$ Programa de Pós-graduação em Educação \\ Universidade do Vale do Itajaí - Univali \\ Itajaí - SC - Brasil \\ \{raabe, andrewbernardes, betoaugusto\}@univali.br
}

\begin{abstract}
This paper presents an experience of production and evaluation of instructional videos aimed at teaching concepts of logic programming. The focus of this paper is to discuss and evaluate the choices made in the production process detailing instructional and technological aspects involved. An evaluation of video lessons was performed by 15 students and enabled to confront the students view with the initial beliefs of the creators of the videos. It was evident the acceptance of the feature for learning support and the need for a more student-centered approach for the production of the videos.
\end{abstract}

Resumo: Este artigo apresenta uma experiência de produção e avaliação de videoaulas voltadas ao ensino de conceitos de lógica de programação. O foco do artigo está em discutir e avaliar as escolhas realizadas no processo de produção detalhando aspectos instrucionais e tecnológicos envolvidos. Uma avaliação das videoaulas foi realizada por 15 estudantes e possibilitou confrontar a opinião dos estudantes com as crenças iniciais dos criadores dos vídeos. Ficou evidenciada a aceitação do recurso no apoio à aprendizagem e a necessidade de uma abordagem mais centrada no estudante para produção dos vídeos.

\section{Introdução}

A disseminação de vídeos instrucionais na internet é notória. Websites de empresas como Adobe, Apple, HP, Microsoft, Samsung, Sony, Dell disponibilizam muitos vídeos do tipo "Como fazer" para seus clientes (MEIJ; MEIJ, 2014). Marcadamente, o lançamento do YouTube em 2005 impulsionou um crescimento na produção e disponibilização de vídeos voltados ao ensino e à aprendizagem.

Videoaulas para conteúdos ligados à aprendizagem de programação são facilmente encontrados. Muitos professores têm criado materiais de apoio à aprendizagem dos estudantes e divulgado na internet. Estes vídeos possuem características marcantes pelo fato de realizarem explicações sobre algum algoritmo escrito em alguma representação, geralmente um código fonte em linguagem de programação.

Mesmo sendo uma prática comum, muito poucos relatos de pesquisa têm sido realizados compartilhando as escolhas referentes à produção técnica e ao planejamento instrucional. E poucos trabalhos avaliam videoaulas sob a ótica dos estudantes. Trabalhos cuja temática são vídeos instrucionais tem sido publicados nos veículos da 
Comissão Especial de Informática na Educação (CEIE) da Sociedade Brasileira de Computação tais como Roesler, Ceron e Andrade (2003), Dallacosta et al. (2004), Pinto (2010) e Oliveira, Santana e Pontes (2010), porém nenhum deles focaliza o aspecto da produção de videoaulas e em particular o formato de videoaula voltado ao uso de Ambientes de Desenvolvimento Integrados (IDEs).

Neste sentido este relato de experiência busca contribuir para discussão acerca de parâmetros para concepção e produção de vídeos instrucionais, mais especificamente para videoaulas direcionadas aos estudantes de programação introdutória. As videoaulas produzidas tiveram como objetivo introduzir conceitos de lógica de programação e auxiliar na ambientação com a IDE Portugol Studio (NOSCHANG et al, 2014).

O trabalho descreve decisões referentes ao processo de produção das videoaulas e a avaliação destas realizada pelos estudantes. No total 36 estudantes de duas turmas de um curso de Ciência da Computação participaram da pesquisa respondendo a um questionário. Destes, 15 estudantes tinham assistido a pelo menos uma videoaula e avaliaram questões relativas ao tempo de duração, qualidade do som, exemplos, explicações e outras características. $\mathrm{O}$ artigo apresenta o processo de elaboração das videoaulas na seção 2 . Na seção 3 apresenta a avaliação realizada e na seção 4 discute as conclusões do trabalho.

\section{Produção das Videoaulas}

Beaudin e Quick (1996) recomendam que na produção de vídeos instrucionais sejam consideradas quatro dimensões: (i) Conteúdo; (ii) Plano Instrucional; (iii) Produção Técnica e (iv) Fornecimento de materiais suplementares. A seguir são detalhadas estas quatro dimensões e também a forma de disponibilização dos vídeos adotada.

\subsection{Definição do Conteúdo dos Vídeos}

Com relação ao conteúdo dos vídeos, foram criados onze vídeos, com o objetivo de explicar os tópicos que são abordados na ementa da disciplina de algoritmos e programação do primeiro período do curso de Ciência da Computação da Universidade do Vale do Itajaí e também de explicar recursos interessantes da ferramenta Portugol Studio, como as bibliotecas por exemplo. Os vídeos criados foram:

Vídeo 1 - Conhecendo o Portugol Studio

Vídeo 2 - Entrada e Saída de Dados

Vídeo 3 - Desvios Condicionais

Vídeo 4 - Operações Relacionais

Vídeo 5 - Operadores Lógicos

Vídeo 6 - Laços de Repetição

Vídeo 7 - Vetores

Vídeo 8 - Matrizes

Vídeo 9 - Bibliotecas

Vídeo 10 - Funções

Vídeo 11 - Parâmetros por Referência e Por Valor 


\subsection{Plano Instrucional}

A produção das videoaulas partiu de um ensaio realizado com objetivo de avaliar três formatos instrucionais diferentes encontrados em videoaulas disponíveis na Internet. Para cada um dos três formatos foi feita uma videoaula, a partir da qual os autores realizaram discussões para definir o formato final a ser utilizado.

No primeiro formato, utilizou-se videoaulas como simulação de um professor em sala de aula, este formato foi inspirado em cursos ministrados pelo Consórcio CEDERJ (2013). Este formato também pode ser visto nas videoaulas apresentadas pelo professor Neitzke (2014) da ULBRA (Universidade Luterana do Brasil), autor de mais de 4600 videoaulas de programação, com mais de 9 milhões de acessos no YouTube. Em Veduca (2014), um site que disponibiliza videoaulas de grandes universidades como Harvard e MIT, este também é o formato predominante.

Como ponto positivo deste formato, está a interação natural com quem está estudando. Fica fácil acompanhar a aula repetindo o exercício em paralelo ao vídeo. $\mathrm{O}$ ambiente da aula é menos formal permitindo pequenas falhas e correções durante sua gravação. Entretanto, os vídeos que utilizam este formato perdem dinamismo ficando cansativos. Neste modelo os primeiros vídeos de teste chegaram a trinta minutos, o que também poderia afastar o estudante interessado em receber informações rápidas.

Em uma segunda tentativa, sobre o modelo do primeiro formato, foi reduzido o número de exercícios e interações com a ferramenta Portugol Studio, ainda mantendo o formato que imita uma aula com um professor. Foi utilizada com maior frequência recursos de aceleração da aula, como colagem de segmentos de código em substituição à digitação de comando a comando. Este formato pode ser encontrado nas aulas iniciais do curso Big Data in Education do site Coursera (Coursera, 2014), ministrado pelo Prof. Rayan Backer, editor do Journal of Educational Data Mining e pesquisador da Columbia University.

Ao contrário do ambiente Coursera, que viabiliza a execução de exercícios a serem respondidos pelo estudante em um ponto específico do vídeo, a utilização deste formato para ser assistido sem pausas (como nas videoaulas produzidas), em pouco minimiza as características negativas do modelo anterior, mesmo com uma redução de $30 \%$ a $50 \%$ no tamanho médio dos vídeos.

O terceiro formato testado foi adotado na produção final dos vídeos. Neste formato a aula é apresentada através de um texto lido rapidamente e as imagens não demonstram a digitação do programa no editor do Portugol Studio, apenas apresentam segmentos de código que ilustram o texto lido. Nos dois exemplos anteriores, o usuário via a digitação de um comando, letra a letra. No formato adotado o texto era colado e o usuário via apenas o comando já digitado, salvo em momentos que a digitação letra a letra era necessária para explicação de determinadas funções da ferramenta, como na explicação do recurso autocompletar. Considerou-se também que o ponto positivo dos modelos anteriores pode facilmente ser alcançado pelo aluno pausando o vídeo para repetir os exercícios em uma IDE do Portugol Studio.

Como ganho, este formato diminuiu o tempo dos vídeos para a média de 5 minutos (aproximadamente $15 \%$ do primeiro modelo). O menor vídeo pôde ser apresentado com apenas três minutos e trinta segundos, e o maior com oito minutos, sem que para isso tenha-se sacrificado a qualidade da explicação. Este formato foi inspirado em videoaulas da ferramenta de modelagem 3D SketchUp (Trimble Buildings, 
2014) e também pelas videoaulas da ferramenta de processos de negócio Bizagi (2014).

Para padronização do diálogo foi definido um texto padrão para todos os vídeos. Os vídeos sempre iniciam com: "Olá meu nome é Roberto, obrigado por se interessar no Portugol Studio, nossa IDE didática para ensino e aprendizagem de programação. O objetivo deste vídeo é...". E terminavam com um desafio, uma frase de estímulo para estudo dos exemplos relacionado ao tema visto, e uma frase: "Mais uma vez obrigado por assistir este vídeo, bons estudos."

$\mathrm{O}$ roteiro de cada vídeo foi pensado para que estes fossem independentes entre si, até o limite do possível. O conteúdo do Vídeo 2 - Entrada e Saída de Dados aparecem em todos os outros vídeos por ser um conteúdo muito básico, mas outros como o do Vídeo 3 - Desvios Condicionais só foram utilizados em outros vídeos quando era de extrema importância.

\subsection{Produção Técnica}

A gravação dos vídeos foi feita em duas etapas. Na primeira o roteiro era lido e apenas o som era gravado. Esta parte influenciou diretamente na qualidade final de cada vídeo. A qualidade da gravação do áudio era fortemente influenciada pelo tamanho da sala onde o vídeo era gravado e até mesmo pelo horário de gravação deste, devido ao ruído do ambiente. Essas variações são fortemente percebidas se unidas em um mesmo vídeo e ocorreram pelo fato de não ter sido possível conseguir um estúdio para essa atividade.

O microfone utilizado foi o encontrado em notebooks e a salas utilizadas não contavam com nenhum ambiente acústico. Isto causou uma dificuldade adicional. A gravação do áudio levou no mínimo 5 vezes o tempo final de cada vídeo. O Vídeo 8 Matrizes, por exemplo, tem 3'42", mas o áudio teve que ser gravado 3 vezes devido a interrupções por ruídos externos e demorou aproximadamente 30 minutos.

A ferramenta, utilizada para gravação e edição do som, assim como a dos vídeos posteriormente, foi o Camtasia Studio, que oferece a um custo relativamente baixo, uma ferramenta de fácil aprendizado e com diversos recursos.

A forma de gravação da parte visual da videoaula foi a que mais evolui entre o primeiro e o último vídeo produzido. Nos vídeos iniciais, o código fonte era colado (control+v) no editor do Portugol Studio, o que foi uma grande evolução se comparado com o primeiro formato testado, onde o código era digitado letra a letra. Entretanto a experiência mostrou que a forma mais produtiva de construir o código fonte durante a gravação do vídeo era digitando todo código e apagando os trechos na ordem inversa em que eles seriam apresentados.

Assim, nos vídeos finais, o código fonte que é visto na gravação foi construído utilizando apenas o comando "Control+Z" do Windows o que possibilitou um número menor de cortes, uma produtividade maior, e uma qualidade notadamente melhor do vídeo final.

A gravação das imagens demorava aproximadamente o mesmo tempo da gravação do áudio. Mesmo utilizando a "técnica" do control+z, os testes precisavam ser realizados manualmente, e o erro na sincronia entre a digitação e o texto lido forçava ao reinício do processo diversas vezes.

Assim, concluído o roteiro, a gravação do vídeo mais a edição final demoravam entre uma hora e meia a duas. Somando o tempo de gravação com a edição do roteiro, 
pode-se estimar o tempo médio de produção de cada vídeo em aproximadamente 4 horas, totalizando $44 \mathrm{~h}$ para produção da 11 videoaulas, descartando o tempo de ensaio com os outros formatos que foram avaliados.

O tempo de escrita do roteiro, que incluía o desenvolvimento do código fonte e testes de sincronização entre a leitura e apresentação deste código, chegou até o extremo de 8 horas no vídeo 5 . Todo este tempo foi utilizado para aprimorar algumas versões da apresentação deste tema de forma que fosse mais empático. Após diversas tentativas, optou-se por deixar de lado o protocolo mais formal dos outros vídeos para apresentar o tema a partir de uma pequena história, que incluiu personagens ilustrados com imagens estáticas.

Desconsiderando o tempo de gravação do Vídeo 5, que foi atípico, na média o desenvolvimento do roteiro dos outros vídeos levou aproximadamente duas horas e meia. Com isso o tempo total de produção dos vídeos foi de aproximadamente 77 horas ( 4 horas $* 11$ videos $+2,5$ horas $* 10$ videos +8 horas $* 1$ vídeo).

\subsection{Fornecimento de Material Suplementar}

Para estimular o estudo de materiais suplementares após a visualização foram incluídos desafios ao final de cada vídeo. Estes convidam o aluno a melhorar o código apresentado nos exemplos com o objetivo de realizar atividades de maior complexidade relacionadas ao tema apresentado no vídeo. Além disso, como a ferramenta Portugol Studio possui um conjunto abrangente com exemplos de códigos fontes, nos vídeos houve o estímulo para o aluno estudar os exemplos que fossem relacionados com o conteúdo explorado.

Os desafios foram incluídos ao final de oito dos onze vídeos, ficando de fora apenas do Vídeo 1 - Conhecendo o Portugol Studio; Vídeo 9 - Bibliotecas; Vídeo 11 Parâmetros por Referência e Por Valor. Os desafios propostos foram concebidos para permitir que apenas com o conteúdo apresentado naquele vídeo fosse possível resolvêlo.

\subsection{Disponibilização das Videoaulas}

Com a versão final de todos os vídeos produzidos, foi criado um canal de divulgação. Foram avaliadas as ferramentas on-line e gratuitas www.youtube.com, www.vimeo.com, www.facebook.com, www.plus.google.com e selecionado o YouTube para utilização como meio de divulgação.

Os motivos que justificam a adoção do YouTube são: (i) Acesso gratuito, sem necessidade de login por parte do usuário; (ii) Possibilidade de incorporar o vídeo em qualquer outra ferramenta ou site; (iii) Alta performance de exibição do vídeo, controlando automaticamente a melhor resolução para cada pessoa que esteja assistindo; (iv) Sugestão automática dos vídeos a interessados, mesmo que estes não estejam procurando por este vídeo. Esta sugestão é feita ao final de cada vídeo que o usuário assistir, utilizando um algoritmo próprio do canal; (v) Possibilidade de monetizar os vídeos através de publicidade, criando a possibilidade de viabilizar uma fonte de recursos que pode ser utilizada na melhoria da ferramenta Portugol Studio. (vi) Integração nativa com o Google Analytics que fornece estatísticas detalhadas de acesso ao canal. $\mathrm{O}$ canal está disponível no endereço http://www.youtube.com/user/portugolstudio. 


\section{Avaliação das Videoaulas}

O objetivo principal da avaliação foi mensurar a qualidade das videoaulas produzidas e a aceitação deste tipo de material didático por parte dos estudantes. Portanto, para tal objetivo avaliou-se os seguintes aspectos: (i) tempo do vídeo; (ii) qualidade do áudio do vídeo; (iii) forma de apresentação do conteúdo; e (iv) como os estudantes se sentiram ao assistir os vídeos, isto é, se ficaram animados e se recomendariam para outros.

Para coletar as opiniões dos alunos foi elaborado um questionário, composto de duas partes. A primeira parte refere-se ao perfil do participante e a segunda aborda à opinião sobre os vídeos. Somente os estudantes que assistiram as videoaulas puderam responder a segunda parte. Foi elaborado um texto com informações sobre a pesquisa e também um termo de consentimento livre e esclarecimento que foi incluído no topo da página inicial do questionário. Abaixo do termo solicitou-se o nome e o código do estudante (fornecido pela universidade) a fim de garantir a fidedignidade dos dados coletados. O questionário foi criado através da ferramenta google forms.

No início do questionário foi informado ao respondente quantas perguntas ele iria responder e quanto tempo aproximadamente levaria. Para a estimativa de tempo foi realizado um teste piloto onde um pesquisador respondeu todas as perguntas e cronometrou o tempo. Houve um cuidado especial na elaboração do questionário a fim de não enviesar as respostas. Portanto, utilizou-se escalas equilibradas. Isto é, oferecer ao respondente a mesma quantidade de respostas negativas e positivas. Por exemplo, para a questão 2.6 ("O que você achou da demonstração de código fonte nas videoaulas?”) há quatro respostas. (1) muito confuso; (2) confuso; (3) compreensível; e (4) muito compreensível. As duas primeiras respostas contrastam de forma equilibrada com as duas últimas.

Não houve nenhum estímulo específico para que os estudantes assistissem as videoaulas. Elas estavam disponíveis em um link na tela inicial da ferramenta Portugol Studio que foi utilizada durante todo o decorrer do semestre letivo. O questionário de avaliação das videoaulas foi disponibilizado para duas turmas da disciplina de Algoritmos e Programação para estes responderem de forma opcional durante as duas últimas aulas em laboratório no semestre. Trinta e seis estudantes responderam sendo que destes quinze informaram ter assistido alguma videoaula e, portanto, responderam todo o questionário. Os 21 alunos que não assistiram limitaram-se a responder a etapa de perfil e uma pergunta descritiva sobre o motivo de não ter assistido aos vídeos.

A análise de conteúdo das respostas sobre porque os alunos não assistiram nenhuma videoaula apontou que $33,33 \%$ dos estudantes não viram nenhum vídeo, pois não tinham conhecimento da existência destes. $42,86 \%$ responderam que não viram por não sentirem necessidade. Por exemplo, um aluno escreveu: "Os exemplo criados dentro do Portugol já foram suficientes para o aprendizado!". O restante dos respondentes $(23,81 \%)$ variou entre "falta de tempo", "preguiça" e "nunca tive muito interesse" (sic).

A segunda etapa do questionário objetivou coletar as opiniões dos alunos sobre a qualidade das videoaulas. Esta foi mensurada através de quatro características: (1) tempo de vídeo; (2) áudio; (3) forma de apresentação do conteúdo; e, por último, (4.1) ânimo e (4.2) recomendação, que compreendem a característica 4 - aceitação pelos estudantes. Além disso, o item 3 está dividido em quatro critérios. São eles: (3.1) fala do narrador, (3.2) exemplos apresentados, (3.3) código-fonte e (3.4) explicações. No quadro 1 , há a relação destas características com as perguntas presentes no questionário. 
Quadro 1. Questões relacionadas às características avaliadas

\begin{tabular}{lll}
\hline \multicolumn{2}{l}{ Características Avaliadas } & Questões \\
\hline \multicolumn{1}{l}{ 1. Tempo de vídeo } & O que você achou do tempo das videoaulas? \\
\hline 2. Áudio & $\begin{array}{l}\text { 3.1 Fala do } \\
\text { narrador }\end{array}$ & O que você achou da qualidade do áudio nas videoaulas? \\
\cline { 2 - 3 } $\begin{array}{l}\text { 3. Forma de } \\
\text { apresentação } \\
\text { do conteúdo }\end{array}$ & \begin{tabular}{l} 
3.2 Exemplos \\
\cline { 2 - 3 }
\end{tabular} & $\begin{array}{l}\text { O que você achou dos exemplos apresentados nas } \\
\text { videoaulas? }\end{array}$ \\
\cline { 2 - 3 } & 3.3. Código-fonte & $\begin{array}{l}\text { O que você achou da demonstração de código fonte nas } \\
\text { videoaulas? }\end{array}$ \\
\hline 4. Aceitação & 4.1 Ânimo & $\begin{array}{l}\text { O que você achou das explicações sobre o conteúdo nas } \\
\text { videoaulas? }\end{array}$ \\
\cline { 2 - 3 } & 4.2 Recomendação & Como você se sentiu ao assistir as videoaulas? \\
\hline
\end{tabular}

A fim de avaliar estatisticamente os resultados as repostas categóricas foram codificadas em números. As questões que tinham uma escala com quatro respostas duas positivas e duas negativas - tiveram a conversão da seguinte forma. A mais positiva recebeu o valor de +2 , a mais negativa recebeu -2 , a resposta negativa com menor intensidade recebeu -1 e a positiva com menor intensidade recebeu +1 . As questões que tinham cinco respostas sendo duas positivas, duas negativas e uma neutra, utilizaram a mesma forma das questões com quatro respostas, todavia a resposta neutra recebeu o valor 0 . Desta forma, a escala codificada varia de -2 (mais negativo) a +2 (mais positivo) onde o zero indica neutralidade ou equilíbrio entre avaliações positivas e negativas. As estatísticas descritivas das características avaliadas são apresentadas no quadro 2.

Quadro 2. Dados quantitativos sobre a qualidade das videoaulas

\begin{tabular}{|c|c|c|c|c|c|}
\hline \multicolumn{2}{|c|}{ Característica Avaliada } & Média & Moda & Mediana & Desvio padrão \\
\hline \multicolumn{2}{|c|}{ Tempo } & $-0,20$ & -1 & -1 & 1,37 \\
\hline \multicolumn{2}{|c|}{ Áudio } & 0,33 & 0 & 0 & 0,72 \\
\hline \multirow{4}{*}{$\begin{array}{l}\text { Forma de } \\
\text { apresentação do } \\
\text { conteúdo }\end{array}$} & Fala do narrador & 1,60 & 2 & 2 & 1,05 \\
\hline & Exemplos & 0,46 & 1 & 1 & 1,30 \\
\hline & Código-fonte & 0,93 & 1 & 1 & 0,88 \\
\hline & Explicações & 0,46 & 1 & 1 & 1,12 \\
\hline \multirow{2}{*}{$\begin{array}{c}\text { Aceitação dos } \\
\text { estudantes }\end{array}$} & Ânimo & 0,33 & 0 & 0 & 0,49 \\
\hline & Recomendação & 2 & 2 & 2 & 0 \\
\hline
\end{tabular}

No quadro 2, os valores positivos indicam avaliação positiva, valores próximos de zero indicam neutralidade ou equilíbrio e valores negativos indicam avaliação negativa. Os resultados apontam uma boa aceitação das videoaulas produzidas considerando a unanimidade na recomendação para outras pessoas assistirem (recomendação) e que apenas uma característica teve média negativa (tempo).

A característica que marcadamente mais desagradou foi o tempo dos vídeos (moda=-1) que indica que os estudantes acharam os vídeos curtos, contraponto a crença dos produtores de que vídeos mais longos poderiam se tornar enfadonhos. Dentre os aspectos ligados a forma de apresentação do conteúdo destacou-se positivamente a fala do narrador. Os exemplos e explicações tiveram média próxima de zero $(0,46)$ indicando um equilíbrio entre avaliações positivas e negativas, o que fica evidenciado também no alto desvio padrão $(1,30$ e 1,12$)$. 


\section{Conclusões}

Ao avaliar as escolhas realizadas à luz dos resultados obtidos considera-se que a produção de videoaulas deve ser um processo realizado de forma a considerar a opinião o público alvo durante o processo de produção. As avaliações realizadas ao final do processo podem elucidar aspectos que não agradaram e que não podem mais serem revisados sem um grande retrabalho. Neste sentido a utilização de abordagens centradas no usuário e com metodologia participativas tendem a reduzir a chance de impactos negativos.

Chamou atenção a baixa atratividade das videoaulas. Dos aproximadamente 70 estudantes que tiveram acesso a ferramenta Portugol Studio, a qual exibia o link para as videoaulas, apenas 15 estudantes $(21,42 \%)$ assistiram-nas. Em parte, pelas explicações inferidas na análise das questões abertas do questionário, a característica se deu pelo fato de a disciplina ser presencial e com forte uso da IDE Portugol Studio em ilustrações e explicações pelos professores.

A ferramenta Camtasia Studio mostrou-se fácil de utilizar e poderosa para produzir efeitos visuais e reduzir o tamanho final dos arquivos. A criação de um canal no Youtube também mostrou-se uma escolha positiva uma vez que não sobrecarregou a infraestrutura de rede da Universidade e ainda ampliou a visibilidade das videoaulas.

Como perspectivas futuras do trabalho pretende-se ampliar a avaliação das videoaulas para uma amostra de estudantes não vinculada a uma disciplina de graduação. Pretende-se usar o canal do Youtube para disponibilização do questionário após a exibição dos vídeos e com isso ter opiniões de usuários de contextos mais diversificados.

Outra perspectiva futura é a criação de vídeos que apresentem a solução para os desafios propostos nas videoaulas. No formato atual, o aluno que tente, sem sucesso, realizar os desafios fica sem saber a correta resposta. Entende-se que este feedback é importante para auxiliar o estudante a autorregular sua aprendizagem, o que conforme Alhazbi e Hassan (2010) ajuda os estudantes de programação a melhorarem suas habilidades.

\section{Referencias}

Alhazbi, S. Hassanh, M. Fostering Self-Regulated learning in Introductory Computer Programming Course, in 18th Annual Western Canada Conference on Computing Education, 2013, pp. 1-4.

Beaudin, Bart P. E Quick, Don "Instructional Video Evaluation Instrument". Journal of Extension, Vol. 34, N. 3, June 1996.

Bizagi: eLearning. 2014, disponível em: <http://elearning.bizagi.com>, acesso em: 05 jul. 2014.

Cederj. Secretaria de Ciência e Tecnologia do Governo do Rio de Janeiro. Curso de Tecnologia em Sistemas de Computação: Fundamentos de programação, 2013, disponível em: < http://www.cederj.edu.br/videoaulas>, acesso em: 05 jul. 2014.

Coursera. Coursera: Big Data in Education. 2014, disponível em: <https://www.coursera.org/course/bigdata-edu>, acesso em: 05 jul. 2014. 
Dallacosta, Adriana; Souza, D.; Tarouco, L.; Franco, S. R. O Vídeo Digital e a Educação, Anais do Simpósio Brasileiro de Informática na Educação - SBIE, 2004.

Meij, H. van der; Meij, and J. van der. A comparison of paper-based and video tutorials for software learning, Computers and Education, vol. 78, pp. 150-159, Jun. 2014.

Narciss, S.; Proske, A.; Koerndle, H.; Promoting self-regulated learning in web-based learning environments. Computers in Human Behavavior, vol. 23, no. 3, pp. 11261144, May 2007.

Neitzke, N. A. Vídeo aulas, 2011, disponível em: <http://www.informaticon.com.br/>, acesso em: 05 jul. 2014.

Noschang, Luis Fernando; Pelz, Fillipi; De Jesus, Elieser A.; Raabe, André. Portugol Studio: Uma IDE para Iniciantes em Programação. Workshop de Educação em Computação, Anais do Congresso Anual da Sociedade Brasileira de Computação, 2014.

Oliveira, F.; Santana, R.; Pontes, M. O vídeo pela Internet como ferramenta educacional, Anais do Workshop de Informática na Escola - WIE, 2010

Pinto, Eduardo Ribeiro G. A produção de vídeo na escola. Anais do Simpósio Brasileiro de Informática na Educação - SBIE, 2010.

Roesler, V.; Ceron, J.; Andrade, M. Aulas remotas on-line utilizando transmissão de vídeo: estudo de caso na Informática da Unisinos, Anais do Simpósio Brasileiro de Informática na Educação - SBIE, 2003.

Trimble Buildings. SketchUp: Video Tutorials, 2014, disponível em: $<$ http://www.sketchup.com/pt-BR/learn/videos?playlist=80>, acesso em: 05 jul. 2014.

Veduca, 2014, disponível em: <www.veduca.com.br>, acesso em: 05 jul. 2014.

Zumbrunn, S. Tadlock, J. Roberts, E. Encouraging Self-Regulated Learning in the Classroom : A Review of the Literature, in Metropolitan Educational Research Consortium (MERC), 2011. 